Western University

Scholarship@Western

Department of Economics Research Reports

Economics Working Papers Archive

1973

Evaluating Public Grants to Private Enterprise where Information is Limited

Peter J. Kuch

Follow this and additional works at: https://ir.lib.uwo.ca/economicsresrpt

Part of the Economics Commons

Citation of this paper:

Kuch, Peter J.. "Evaluating Public Grants to Private Enterprise where Information is Limited." Department of Economics Research Reports, 7324. London, ON: Department of Economics, University of Western Ontario (1973). 
Research Report 7324

EVALUATING PUBLIC GRANTS TO PRIVATE

ENTERPRISE WHERE INFORMATION IS LIMITED

by

P. J. Kuch ${ }^{*}$

* I wish to thank my colleagues Kenneth Avio, Kul Bhatia, Donald McFetridge, Thomas Romer and Robert Woodward for their helpful comments on an earlier draft of this paper. The responsibility for any remaining errors is solely mine. 
Introduction

It is commonplace for government agencies to provide financial assistance to private businesses. This assistance can take a variety of forms, including - outright grants of public funds, subsidized loans, or tax abatements. $^{1}$ As a result of the institutional setting in which public expenditure decisions are made, it is frequently necessary for proposed grants to be evaluated as to their social desirability, seriatim, without reference to a previously specified budget constraint or full knowledge of potential alternative public expenditures. Furthermore, proposals normally refer to a single projected output level or a narrow range of output levels. Information about alternative levels of operation, and hence the effect of varying levels of support is extremely limited. In addition, subsidies cannot normally be paid on the basis of ex post performance. These factors preclude considerations of optimality and perforce limit any analysis to the question of whether a specific subsidy will, on balance, make society betteroff.

While traditional cost-benefit procedures ${ }^{2}$ appear we 11 suited to this institutional setting, the straightforward application of cost-benefit analysis to the evaluation of public grants is likely to generate confusion, and quite possibly yield erroneous results. One source of difficulty is a confusion about the relevant public investment. Cost-benefit analysis operates from a perspective in which the government is assumed to be the agent of production and as such must evaluate a public investment consisting of the opportunity costs of all of the resources used in the project. On the other hand, where one is considering subsidies paid to the private sector, 
the primary agent of production is a private firm; government involvement is limited to provision of the grant. In such a situation, the public investment that must be evaluated is the grant.

Another source of difficulty is that transfers of income within a society are omitted from cost-benefit analysis on the grounds that the analysis is primarily concerned with allocative efficiency and not with changes in income distribution. However, in the case of a subsidy, the mechanism of public investment is in fact a transfer of resources, and any evaluation of this sort of public expenditure should involve determining the extent to which the transfer improves resource allocation as opposed to merely changing the income distribution. If at the outset the magnitude of the grant is excluded from the analysis it becomes impossible to evaluate a proposed grant in terms that allow it to be compared with other proposed public expenditures.

To ignore the magnitude of the public grant in the evaluation of a particular subsidy scheme is to implicitly assume that these public funds have no opportunity cost. If the supply of public funds is limited, making the grant will preclude undertaking other public projects or programs. Even if there is no explicit budget constraint, the raising of additional public funds to finance the grant will displace private sector investment and consumption. In either case there is an opportunity cost that need not correspond to the value in alternative uses of the inputs employed by the recipient firm.

The remainder of the paper is devoted to presenting a framework for evaluating public assistance to private firms that is operationally suited to the existing decision-making environment and avoids the difficulties 
inherent in traditional cost-benefit analysis. It is based on the premise that apart from meeting certain income redistribution objectives, the subsidization of a business venture must be justified in terms of the existence of positive externalities associated with the product of the enterprise. It follows from this that the criteria used for evaluating public grants to the private sector should draw heavily on the theory of externalities. Thus, the body of the paper commences with a discussion of the circumstances in which it is appropriate for the government to make grants available to private firms. This is followed by a brief summary of the relevant aspects of externality theory, which essentially deal with the use of subsidies to achieve optimal resource allocation. Based on these concepts, criteria are then developed for use in situations where limited information and institutional constraints confine the evaluation of grants to issues of allocative improvement and income redistribution. The Rationale for Publicly Subsidized Private Production

A grant of public funds to business, as well as any other form of fiscal activity, can only be evaluated in the context of the objectives it is supposed to achieve. In order to define the appropriate objectives for public grants it is necessary to consider the circumstances under which the government should become involved in subsidizing production in the private sector.

Income transfers should not be the primary rationale for public subsidies to private firms. Certainly where the primary concern is a prevailing maldistribution of income, a general system of income taxes and transfers is more suitable than a subsidy aimed at a specific economic activity. In the latter case the income flow is confined to only the owners of the factors of production employed by the activity singled out for aid. 
Furthermore it is hard to predict in advance how this increased income will be divided among the owners of the different factors involved. The bulk of it may go to foreign owners of capital, or it may be appropriated by management. If the government's objective is to redistribute income, diverting the income transfer through specific businesses, as opposed to making payments directly to the target individuals, will produce an unnecessary distortion in resource allocation. Resources will be attracted from nonsubsidized to subsidized enterprises, resulting in a decline in the output of the former and increase in the output of the latter.

Thus it becomes apparent that government should not subsidize private business unless it specifically desires to alter the allocation of resources in a way that will lead to an increased output of the goods produced by the subsidized firms. This sort of interference in the market allocation prom cess is appropriate where the relevant firms are not producing sufficient quantities of, or are not producing at all, some socially desirable good. 3 Insufficient production may occur either because firms are unable to obtain compensation for a portion of the benefits they would bring about or else because they would be required to bear costs in excess of those actually borne by society. The former situation will arise where there is either some joint consumption of the firm's output ${ }^{4}$ or a spin-off of intermediate goods from its production processes. The latter situation, where private costs exceed social costs, is generally associated with imperfections in the labour and capital markets. In each of these instances the production of the good can be viewed as giving rise to external benefits. 5

Most non-trivial examples of joint-consumption phenomena involve commodities that are so highly indivisible as to require a degree of 
subsidization which effectively removes them from the sphere of private sector allocation. Here, one is no longer dealing with an externality, but with a public good. Market allocation breaks down completely and must be replaced by public allocation mechanisms. Whether the particular good is actually produced by a private firm or by a public agency is immaterial for the purposes of analysis. ${ }^{6}$ The few examples of instances in which joint consumption externalities might properly be used to justify publicly subsidized private production (that is, where one is still essentially dealing with private sector allocation) all seem to be drawn from the arts. Significant examples of external benefits stemming from production processes themselves are more commonplace. Grants are often justified in terms of the research and development and the on-the-job training components of the recipient firms' activities. In those situations where other users will have free access to the technological innovations resulting from the research and development activities, or where the on-the-job training is not specific to the recipient firm, it is likely external benefits will flow from the production of the subsidized good.

Particularly in the case of labour, geographic immobility of factors and downward inflexibility of their prices frequently create situations where a prospective employer must pay an unemployed or underemployed factor an amount in excess of its opportunity cost. ${ }^{7}$ This payment in excess of the opportunity cost can be considered an external benefit accruing to the factor, but which is generated by the firm which employs it. ${ }^{8}$ An argument along these lines seems to implicitly lie behind the use of public subsidies to encourage industrial location in underdeveloped or depressed regions. 
Imperfect capital markets may produce situations where risk premiums do not represent true risk. As a result, certain firms could be required to pay interest rates in excess of the expected productivity of their capital. This would cause the present value of private costs to exceed the present value of social costs and could justify subsidizing loans to these firms. In summary, then, the arguments justifying the use of public grants to subsidize private enterprises must hinge on the existence of external benefits flowing from these particular enterprises. Unless it can be shown that there are benefits which cannot be appropriated by the firm, but which when they are added to the firms' revenues produce a total of social benefits in excess of social costs, there is no theoretically sound reason for encouraging the firm to produce more than market forces alone would dictate.

\section{The Received Wisdom}

The Optimal Subsidy

In situations where positive externalities exist, but where the number of potential beneficiaries make the use of negotiated settlement infeasible, a Pigouvian subsidy given to the source of the externality is generally prescribed as the appropriate method for promoting optimal resource allocation. 9 The subsidy is just equal to the value of the external benefits that are generated, the marginal grant being equal to the marginal external benefit. This can be viewed as either shifting the externality producer's marginal revenue up to the level of marginal social benefits, or else shifting his marginal costs down to the level of marginal social costs, depending on where the divergence exists. In either case, profit maximizing behaviour will lead him to produce at the socially optimal output level. 
Consider an enterprise for which at certain output levels social benefits $(S B)$ exceed private revenues $(R)$ and/or out-of-pocket costs 10 (C) exceed social costs (SC). At these output levels net social benefits (NSB) will exceed private profits (P). 11 Assume that the output at which profits are maximized differs from the output at which net social benefits are maximized. In fact, let profits be negative at this output leve1. This situation is depicted in Figure 1 below. Ieft to its own devices the firm

\section{Figure 1}

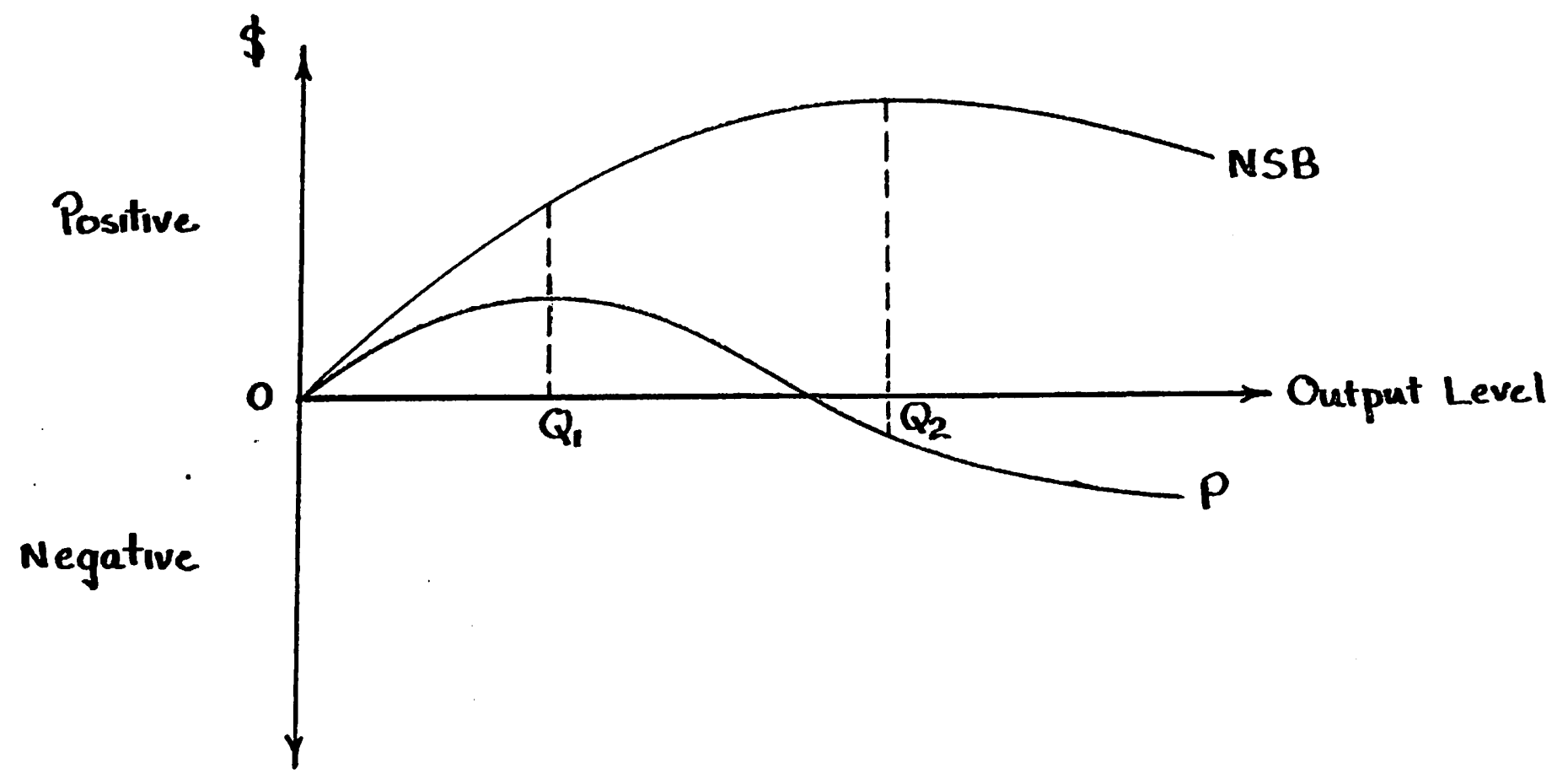

would produce at $Q_{1}$, where profits are maximized. However, by giving it a grant that equals the magnitude of the external benefits (EB) at each output level, which is equivalent to the difference between net social benefits and profits (NSB-P), ${ }^{12}$ the firm will be led to produce at $Q_{2}$, 
the output at which social benefits are maximized. Such a grant makes the firm's profit function coincident with society's profit function.

Thus, if it is to generate an optimal allocation of resources, the grant must vary with the level of production and at each output it must equal the difference between net social benefits and private profits (NSB-P). 13

\section{The Allocation of Subsidies}

Ideally, subsidies should be provided to every enterprise that would potentially yield external benefits. ${ }^{14}$ These subsidies should be provided until the net social benefits generated by each enterprise are maximized. At that point a marginal increase in the grant to any of the externality-generating firms would not bring forth any additional net social benefits. If one assumes the following sort of functional relationship between net social benefits and the grants to each firm: NSB $=\sum_{i} f_{i}\left(G_{i}\right), 15$ then maximizing NSB requires that $\frac{\partial N S B}{\partial G_{i}}=0$ for all $i$. Optimal resource allocation necessitates that sufficient funds be made available for grants to achieve this result.

If for some reason the total funds available for grants are constrained to be less than this amount it will be impossible to achieve optimality. In such a situation the "second-best" solution requires that the funds be allocated so that the marginal net social benefit per dollar of grant to each enterprise is identically equal to the shadow price of the constrained funds. ${ }^{16}$ Carrying on with the previous example, if NSB $=\sum_{i} f_{i}\left(G_{i}\right)$ is to be maximized subject to the constraint $\sum_{i} G_{i} \leq \bar{G}$, i.e., maximize $V=\sum_{i} f_{i}\left(G_{i}\right)+\lambda\left(\bar{G}-\sum_{i} G_{i}\right)$, 
then $\frac{\partial N S B}{\partial G_{i}}=\lambda$ for all $i$. Funds should be given to each firm until the marginal net social benefit from additional funds falls to $\lambda$, which will be strictly positive if the constraint is binding.

Limitations to the Usefulness of this Theory

None of this theory is really new, but its applications to public expenditure policy has been limited because of its focus on achieving optimal resource allocation which requires either that, ex post, subsidies be paid to all activities which generate external benefits, or that net social benefits and profits at all output levels be known for all activities which generate or could potentially generate external benefits. Neither of these requirements can in reality be fulfilled. Institutional factors prevent the tying of the subsidy payment to the actual generation of the externality. Furthermore, information is severely limited both with respect to the activities which can or do generate external benefits and as concerns the shape of individual net social benefit and profit functions. These factors normally preclude considerations of optimality, limiting the scope of analysis to asking whether individual grants will improve social welfare and to ranking grant proposals in terms of their desirability where funding is limited. Even where funds can be presumed to be scarce, the precise size of the budget is rarely known in advance. The evaluation and ranking of proposals are inputs in the budgeting process itself.

In addition, the theoretically optimal subsidy scheme would be determined ignoring income distribution effects by implicitly assuming that costless taxes and transfers could be used to achieve any desired income distribution. However, governments normally lack the degrees of freedom necessary if they are to totally divorce allocation decisions from considerations of equity. Therefore, while subsidies to private business should not be 
used if the primary intent is to redistribute income, these subsidies will, nonetheless, generally have a redistributional effect. Thus it is reasonable to expect that grant proposals will also have to be judged in terms of their distributional consequences.

When Does a Grant Improve Social We1fare?

Although it is normally impossible to consider a particular grant with reference to the attainment of optimality, it is possible to determine whether a proposed grant, of say G dollars, to a particular enterprise is likely to improve social welfare. In order to simplify the discussion, assume that the proposal refers to a specific projected output level; lack of information precludes consideration of alternative output levels. 17 View society as being composed of three sets of individuals, which may overlap-the purchasers of the good, the producers of the good, and the potential recipients of the external benefits.

In the context of improving social welfare, the first question to be asked is: Is it socially desirable to have the good produced at all? The answer is found by comparing the present value of all of the benefits (external and direct) of the good with the present value of the opportunity cost of all of the resources used in its production. Hence is NSB $>0$ ? If the social benefits exceed the social costs, it is obviously desirable to have the good.

The next question to be asked is whether it is desirable to use a grant of $G$ dollars to precipitate the production of the good by the private sector. ${ }^{18}$ The answer to this question is found by comparing the present value of the external benefits (EB) generated by the good with the magnitude 
of the grant. Is $E B \geq G$ ? If the recipients of the external benefits bear the tax burden of the grant, the fact that external benefits are at least as large as the grant implies that no group will be made worse off by the use of the grant. EB is the most the external-benefit recipients would be willing to pay. The payment of a larger sum would make them worse off. The other group of beneficiaries, the purchasers of the good, will never pay the producer more than their valuation of the benefits they receive. 19 The correspondence between the persons receiving external benefits and the persons bearing the tax burden of the grant is not necessary if one is willing to interpret $E B \geq G$ as meaning potential transfers are possible between benefit receivers and taxpayers such that no one is made worse off by the grant. This is actually consistent with the use of NSB $>0$ as the general condition for the social desirability of the good. The welfare interpretation of positive net social benefits is that potentially the gainers could compensate the losers and still be left better off. 20 However, this line of reasoning cannot be applied to potential transfers from the grant recipient to the rest of society. G must be net of all transfers from the producer of the good, otherwise the magnitude of the subsidy loses any significance for the purposes of analysis, and private sector production involving an infinite grant would be acceptable so long as NSB $>0$.

The discussion thus far has only considered external benefits. It is certainly possible that the production of the good in question, brought about by the grant, will also generate external costs. External costs require a treatment that is symmetric to that given external benefits to 
the extent that if external costs exceed external benefits the output of the good should be taxed rather than subsidized. Thus, for the sake of of generality the rule $E B \geq G$, should be interpreted as meaning that the present value of net external benefits should be at least as large as the grant.

It might be argued that the appropriate criterion for publicly subsidized private production is NSB $\geq$ G. However, this rule is likely to treat firms requesting assistance inequitably. 21 It may allow grants that are either too small or too large, depending on the entrepreneur's potential profits (P) without the subsidy. As they have been defined here the net external benefits are equal to the difference between net social benefits and the entrepreneur's profits $(E B=N S P-P)$. If the grant can only be as large as the net social benefits, where profits would be negative $(P<0)$ the entrepreneur will always be undercompensated for the external benefits he is producing. Whereas, if the profits would be positive $(P>0)$, a grant may be allowed which overcompensates him for the external benefits. It is only where there would be zero profits $(P=0)$ without the grant that the two criteria are equivalent.

This is most easily demonstrated by referring to Figure 2 . If the grant proposal involves producing quantity $Q_{1}$, using the rule $N S B \geq G$ implies a maximum grant of ' $a b$ ' which leaves the entrepreneur uncompensated for his loss of 'bc'. On the other hand, if the proposal involves producing quantity $\mathrm{Q}_{2}$, the maximum grant ' $\mathrm{df}$ ' would result in an overcompensation of 'ef', the amount of his pre-grant profits. 


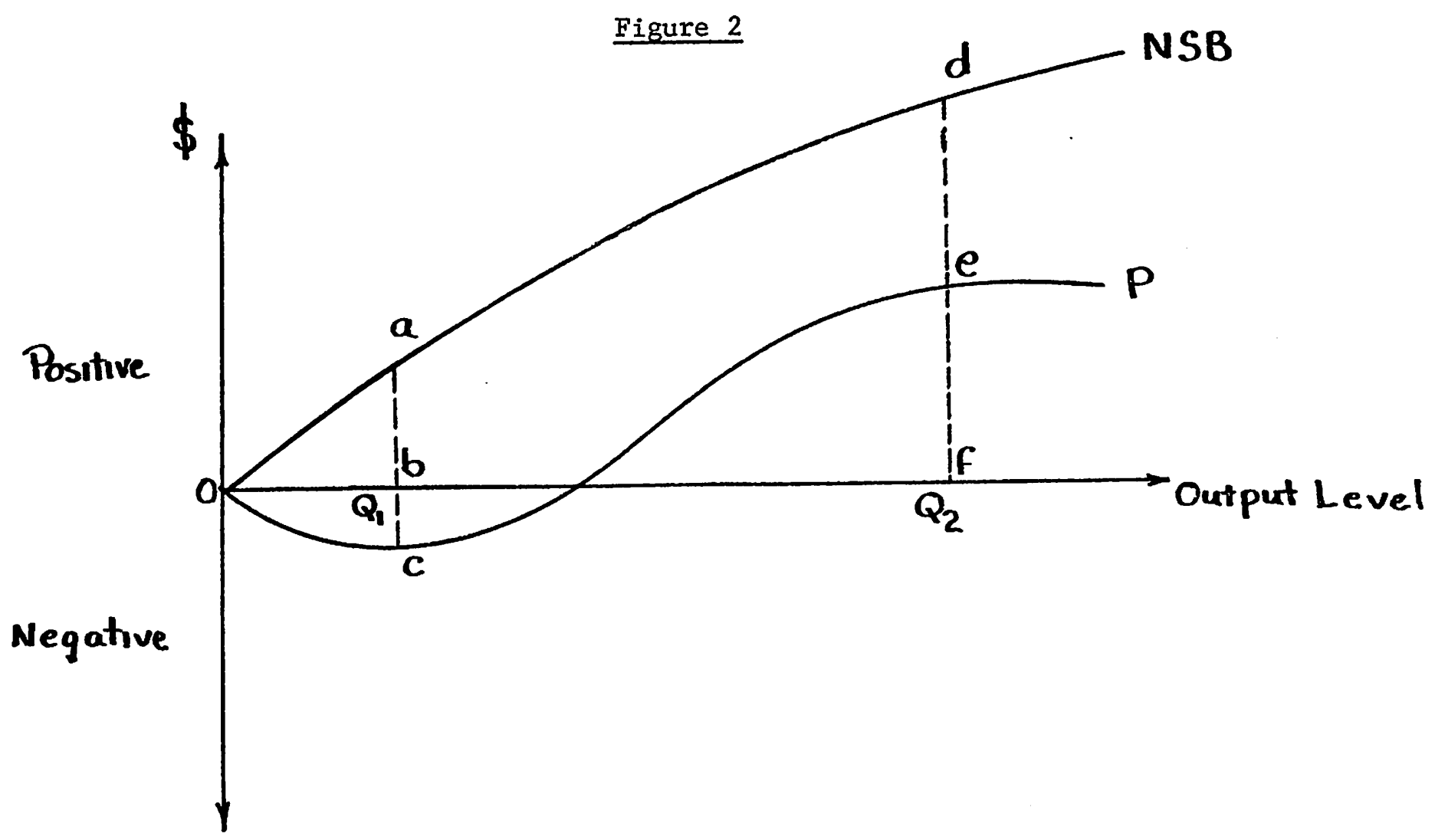

\section{Distributional Consequences of the Grant}

With respect to a particular subsidy, once it has been determined that the good involved is socially desirable (NSB $>0$ ) and that society receives net external benefits that are at least as large as the grant $(E B \geq G)$, it is worthwhile to determine if the grant requested is larger than should be required to induce production of the good. Essentially this involves seeing how the grant alters the entrepreneur's income relative to the rest of society.

Where $P$ represents the entrepreneur's potential profits from producing the good without the grant, let $P_{n}$ be the profits he would earn from 
his best alternative investment involving the same outlay. ${ }^{22}$ Then if $P_{n}-P=G$, the entrepreneur's relative income position is not changed by the grant. His inputs are earning just what they would receive in alternative uses. Where $P_{n}-P<G$, the grant is producing an increase in his relative income position; some or all of his inputs are being paid more than their opportunity cost. Conversely, if the entrepreneur only required a grant such that $P_{n}-P>G$, he would be accepting a return on his inputs lower than he could earn elsewhere and his relative income would fall. Hence, where a grant provides a profit greater than that otherwise available to the entrepreneur $\left(P_{n}<P+G\right)$ it is probably safe to conclude that there exists a more inexpensive way of bringing about the production of the good.. Such a grant covers more than the opportunity costs of the resources involved; it includes an income transfer to the entrepreneur as we11. ${ }^{23}$ of course, it may be the case that such a transfer can be justified by the social consensus concerning an equitable income distribution.

\section{Concluding Comments}

The outcome of the foregoing discussion is that where public grants are to be justified on efficiency (as opposed to distributional) grounds the existence of positive net social benefits is a necessary but not a sufficient condition for their desirability. It must also be the case that the size of the grant not exceed the magnitude of the net external benefits generated by it. If both of these conditions are satisfied the grant can be said to make society better off. The degree to which the grant is less than the sum of net external benefits is the degree to which the private firm is not extracting the full value of the external benefits it is creating. 
A more meaningful measure of the income redistribution consequences of the grant is obtained by comparing the gross of grant rate of return the firm would earn with rate of return it could earn with the same resources in their best alternative use.

At some stage of the governmental decision process, proposed expenditures should be compared. If more than one grant proposal is being considered as an alternative use for a limited amount of funds, each candidate must satisfy the conditions that its net social benefits are positive and that the net external benefits it generates are at least as large as the grant. Proposals satisfying both of these conditions can then be ranked in descending order according to the net social benefits generated per dollar of grant. Non-grant proposals can be included in the ranking by calculating the net social benefits they would generate per dollar of public-sector expenditure. Proposals can also be ranked with respect to alternative, or additional constraints, particularly relating to the distributional consequences of the grant. The appropriate ranking index in each case can be derived from the first order conditions of the corresponding constrained maximization problem.

Even though a particular grant proposal is framed around a very limited range of production levels, there is no reason for the granting agency to be satisfied with this paucity of information if it can elicit data about alternative production levels by offering grants both larger and smaller than the sum requested. Obviously, if the initially proposed output will lead to the highest post-grant profits the firm will probably engage in strategic bluffing. However, this is not likely to be more of a problem with subsequent iterations than existed with the initial proposal. In fact, it seems reasonable that enough information can be gleaned from 
such a procedure to allow the selection of a production level that is superior to the one initially proposed, and is in fact a local optimum on the net social benefit function. 


\section{Footnotes}

1The terms "grant" and "subsidy" will be used interchangeably to refer to all of these forms of public assistance.

2 These procedures generally involve a comparison of the discounted sums of social benefits and costs generated by a project, where benefits are defined as aggregate consumption opportunities gained (measured by the consumers' willingness to pay for them), and where costs are defined as aggregate consumption opportunities foregone (measured by the opportunity cost of the resources used in the project). The comparison may involve the calculation of net social benefits, a benefit to cost ratio, or an internal rate of return. For a standard discussion of this methodology see A. R. Prest and R. Turvey, "Cost-Benefit Analysis: A Survey," The Economic Journal, LXXV, 300, December 1965, pp. 683-735.

${ }^{3} \mathrm{~A}$ good is deemed socially desirable if it generates social benefits which are at least as large as the social costs it imposes. An insufficient quantity of the good is being produced, if the social benefits that would be derived from an additional unit of the good exceed its social cost.

${ }^{4}$ This adversely affects the firms ability to exclude non-payers from consuming portions of its output.

${ }^{5}$ It should be pointed out here that external benefits may flow from a consumption activity involving a particular good. In such a situation public subsidization may very well be warranted, but the subsidy should be paid to the consumer, not the producer of the good. It is the act of consumption that produces the externality, which might be called a "consumption spillover." However, it is hard to think of an example of this sort of externality that is not contrived or trivial.

${ }^{6}$ Conventional cost-benefit analysis should be used in either case.

${ }^{7}$ As concerns the appropriate measure of this opportunity cost see E. J. Mishan, Cost-Benefit Analysis: An Informal Introduction (London: George Allen and Unwin, Ltd., 1971), pp. 71-78.

${ }^{8}$ See A. C. Harberger, "On Measuring the Social Opportunity Cost of Labour," in A. C. Harberger, Project Evaluation: Collected Papers (Chicago: Markham Publishing Co., 1972), pp. 165-167.

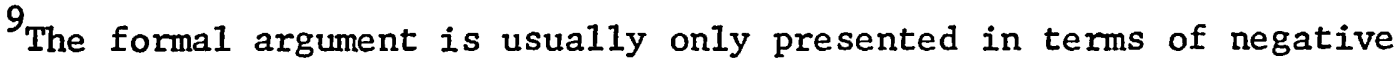
externalities and Pigouvian taxes because of the obvious symmetry between the two cases. For a recent discussion of the efficiency of Pigouvian taxsubsidy schemes in dealing with externalities see W. J. Baumol, "On Taxation and the Control of Externalities," American Economic Review, LXII, No. 3, June 1972, pp. 307-322. 
${ }^{10}$ These are defined to include a normal return to capital.

$$
\begin{aligned}
&{ }^{11_{N S B}}=S B-S C \\
& P=R-C .
\end{aligned}
$$

${ }^{12} \mathrm{~EB}=\mathrm{SB}-\mathrm{R}+\mathrm{C}-\mathrm{SC}=(\mathrm{SB}-\mathrm{SC})-(\mathrm{R}-\mathrm{C})=\mathrm{NSB}-\mathrm{P}$.

${ }^{13}$ Where NSB $-\mathrm{P}<0$, the optimal subsidy is negative, a tax.

${ }^{14}$ Using the preceding terminology, wherever NSB $-\mathrm{P}>0$.

${ }^{15} G_{i}$ represents the grant given to each externality producing firm (i). For each firm the function $\mathrm{NSB}_{i}=f_{i}\left(G_{i}\right)$ is assumed to be concave and continuous.

16 This shadow price is the increase in net social benefits that would result from a marginal increase in the supply of funds available for grants.

${ }^{17}$ For all intents and purposes, the good can only be produced in a fixed quantity, if it is produced at all.

${ }^{18}$ The alternative is to have it produced in the public sector.

${ }^{19}$ If the demand for the good is relatively inelastic there is likely to be significant consumers' surplus (CS) that is not captured by the entrepreneur. In that case a less restrictive criterion could be used,

$$
\mathrm{EB}+\mathrm{C} \geqq \mathrm{G}
$$

${ }^{20}$ Mishan defines this as indicating a "potential Pareto improvement." See E. J. Mishan, Cost-Benefit Analysis: An Informal Introduction (London: George Allen and Unwin, Ltd., 1971), pp. 316-321.

${ }^{21}$ I wish to thank Thomas Romer for pointing out this difficulty.

22 These alternative profits must be exclusive of other public subventions.

${ }^{23}$ This says nothing about the magnitude of any implicit transfers to labour employed by the entrepreneur, since their wages reduce $P$ and $P_{n}$ by the same amount. Transfers to labour, in the sense of being market required payments in excess of their opportunity wages are a component of EB. 


\section{References}

Baumol, W. J., "On Taxation and the Control of Externalities," American Economic Review, LXII, No. 3, June 1972, pp. 307-22.

Harberger, A. C., "On Measuring the Social Opportunity Cost of Labour," in A. C. Harberger, Project Evaluation: Collected Papers (Chicago: Markham Publishing Co., 1972), pp. 157-183.

Mishan, E. J., Cost-Benefit Analysis: An Informal Introduction (London: George Allen and Unwin, Ltd., 1971).

Prest, A. R., and Turvey, R., "Cost-Benefit Analysis: A Survey," The Economic Journal, LXXV, No. 300, December 1965, pp. 683-735. 